\title{
Children and youth transport in different urban morphological types
}

\author{
Satu Sarjala \\ Tampere University of Technology, Finland \\ satu.sarjala@tut.fi
}

\section{Ari Hynynen}

\section{Tampere University of Technology, Finland ari.hynynen@tut.fi}

\begin{abstract}
As demonstrated in many earlier studies, the qualities of physical environment have great impacts on physical activity (PA) behavior. However, studying individual built-environment variables often produces contradictory effects between studies. To overcome this, we composed multivariate environment types using principal component analysis that takes notice of the inter-correlations between physical-environment variables. To get a realistic view of the places children and adolescents visit in their daily life, we used mapping methodology in which children themselves defined their important places. Based on 16 built-environment variables, six built-environment types were composed around these places.

We found that walking and cycling were most prominent in residential environments and least common in mixed-use business districts. Areas with big commercial buildings as well as green environments had the highest proportions of car use. Most places, in general, were visited with friends, but most typically areas with big commercial buildings and mixed-use business districts were reached in the company of friends. Relatively many places were visited alone in residential areas.
\end{abstract}

\section{Introduction}

One of the main motives to study physical activity (PA) patterns in different urban environments is to develop urban-planning and design policies. To find ways to inform urban planners and policymakers, we have to pose ancillary questions: How do we design a city that encourages people to use their muscles for moving, and how do we avoid making built environments (BE) that do the opposite? To answer these questions, we need to define the key features of an urban environment that support active transportation. In this context, children and adolescents form a critical group, since the foundations for adulthood health are built in youth (Malina 2001). Based on this reasoning, it seems that the qualities of urban environments might have remarkable impacts on national health.

Copyright 2015 Satu Sarjala, Anna Broberg, \& Ari Hynynen http://dx.doi.org/10.5198/jtlu.2015.803

ISSN: 1938-7849 | Licensed under the Creative Commons Attribution - Noncommercial License 3.0

The Journal of Transport and Land Use is the official journal of the World Society for Transport and Land Use (WSTLUR) and is published and sponsored by the University of Minnesota Center for Transportation Studies. This paper is also published with sponsorship from WSTLUR and the Institutes of Transportation Studies at the University of California, Davis, and the University of California, Berkeley. 
There is plenty of research on PA of young people in urban settings. However, there are some deficiencies that make the results quite tricky to put into operation in urban planning and design. Statistical methods generally used in studies typically emphasize the importance of individual variables as effective factors in supporting — or discouraging — active transportation. In addition to this, these variables might sometimes indicate totally different effects in different studies. For example, in many studies performed in the United States, residential density is discovered to have a significant positive connection with walking among both children and adults (Frank et al. 2007; Frank et al. 2008) and in males and females (Kerr et al. 2007). On the other hand, Cradock et al. (2009) reports that housing density is not significantly associated with any PA outcome of adolescents. Also in recent studies performed in Europe, the connection between residential density and active travel among children and adolescents seems either negative or neutral. De Vries et al. (2010) report no connection between residential density and active transportation among 6-to 11-year-old children. For adolescents age 11 to 14 years, the density of housing seems to correlate negatively with active transportation, as the odds of walking or biking to a meaningful place decreased in densely built-up residential areas and increased in areas dominated by single-family housing (Broberg, Salminen, and Kyttä 2013).

The conflicting results presented above might arise from cultural differences between countries and continents. But it is still problematic that individual variables like "residential density" are not able to explain the impacts of the total environment on human behavior. For the statistical methods to really be capable of taking into account the joint effect of several factors, built environment (BE) should be quantified to the level where the availability of proper data causes problems. From the standpoints of human behavior and experience, $\mathrm{BE}$ comprises a highly qualitative category. Therefore, individual factors are not very useful in urban-design practices, which focus especially on total environment. In addition to "residential density," other environmental variables recognized in studies are, for example, network connectivity (Kerr et al. 2007; Frank, Andresen, and Schmid 2004; Frank et al. 2007, 2008; Broberg, Salminen, and Kyttä 2013; Villanueva et al. 2012, 2013), density of bus stops (Carr, Dunsiger, and Marcus 2010; Broberg, Salminen, and Kyttä 2013) or land cover of single-family housing (De Vries et al. 2010; Broberg, Salminen, and Kyttä 2013). All of these factors have led to more or less diverging effects in different studies conducted in varying countries and cities, among different age and gender groups.

Although there is no consensus reached with the effect of BE variables on youth PA, many studies report that land-use mix is found to have a positive association with PA among all age groups. Recent reviews conducted by Ding et al. (2011) and Pont et al. (2009) reported that objectively measured land-use mix is one of the most consistently positively associated $\mathrm{BE}$ variables with PA and active transportation in both children and adolescents. Moreover, the odds of walking for transport in children and adolescents seem to almost double in environments with more than one land use (Frank et al. 2007). In respect to weekly bouts of moderate to vigorous PA, land-use mix is discovered to have a significant positive correlation among adolescent boys, but no correlation is found among girls (Boone-Heinonen et al. 2010). Also, in studies concerning adults, land-use mix is found to be one of the most important variables affecting PA. It is even demonstrated to be the only $\mathrm{BE}$ variable with great significance in choosing active over passive transportation in adults (Cervero and Duncan 2003).

The rather convergent results reported above suggest that land-use mix is able to cover the complex features of total environment quite well. The variability of functional properties of buildings and sites might indicate morphologically diverse built environments with interesting vistas and spatial experiences and atmospheres. But still, multifaceted functionality alone does not exclude features that might, in some cases, discourage active transportation due to, for instance, congestion. Land-use mix, as well as residential density, might indicate urban environments that support PA, but it is likely that there are also other important factors. These two factors are sub-constituents of total environments, which can 
be interpreted as certain urban morphological types, when studied from the standpoint of PA. In this article we aim to introduce starting points for recognizing these types.

In the context of our study, urban morphological types could be understood as aggregates composed of diverse form properties of physical structures and urban space. Types as such could not be incorporated in any plan, since they are only generalized models of the properties. Instead, it is possible to develop them into concrete planning and design solutions for different parts of a city. It is important to notice that morphological types are always tied to urban processes, whether social, economic or political, among others. Morphological types are very practical in urban design, since they form a link between abstract ideas and concrete forms (See Moudon 1994, 1997).

In working with types, it is crucial to avoid vague descriptions like, for example, "dense urban core" or "suburban single-family housing area." These kinds of morphological types prevail in colloquial language, but they are way too rough for urban-design purposes. They do not add to our understanding of effective factors of PA in urban environments. Moreover, unconscious application of them might result in reproducing existing types that only ostensibly support desired behavior. Due to this, the environmental types in our research have to be constructed from a bottom-up manner, without fixed presumptions, based on the behavioral aspects of the target groups.

This kind of an approach requires specific research design. In this study, we started by mapping places that our young informants felt meaningful to go. After mapping, the respective urban environments were analyzed morphologically. We used principal component analysis to compose multivariate profiles of the physical environment around meaningful places that children marked on maps. We further clustered the environments around these meaningful places based on the component loadings to create urban morphological types. These variables provide the cornerstones for specific urban BE types that should produce similar activities regarding, for example, mode of transportation.

With the composed BE types, the aim is to find the most associated joint effects of the physical environment factors with youth active and independent transportation. It is crucial to avoid overinterpretation and vague definitions in naming these types and instead describe them accurately based on the analyzed BE characteristics the types consist of. In this way, the BE types also can be useful for urban-planning purposes.

In addition, the possible motivation to go to the places was studied by querying the activities and meanings that the places provide for the youth. To analyze the characteristics of the physical environment that offer children intriguing possibilities for various activities, rich experiences, and social interaction, we applied the concept of affordance by Gibson (1986). The term "affordances" has traditionally referred to the perceived opportunities and restrictions concerning a person's actions in a given environment (Heft 1988, 2001) but can be expanded to include also the emotional, social, and socio-cultural opportunities and restrictions that an environment offers (Kyttä 2002). The concept of affordances breaks the subject-object dichotomy: An affordance is neither a characteristic of the environment nor a characteristic of the individual, but rather it is something between them. An environment needs to have something that an individual can perceive as an opportunity, but such a perception will only be formed if the individual is inclined (e.g., by his physical proportions or social needs) to find his or her equivalent in the environment.

\section{Methodology}

The Internet-based SoftGIS -method (Kahila and Kyttä 2009) enabled the target groups to pinpoint meaningful places on the map by themselves. The respondents used the Internet interface to mark places on a map that were functionally, emotionally, or socially meaningful. Further, they could tick which affordances were actualized in the meaningful place they had marked on the map. The taxono- 
mies used were based on previous studies in Finland (Broberg, Kyttä, and Fagerholm 2013; Kyttä, Broberg, and Kahila 2012), and included functional, emotional, and social affordances. The respondents were asked to: "Think of the places in your environment that are good or bad for doing things, that have good or bad social atmosphere, or where you feel good or bad" (see Figure 1). The location of the meaningful place was marked on the map and then the detailed affordance that the place provides was selected by ticking from the list of affordances. Moreover, the affordance lists were modified to include equal amounts of positive and negative affordances. Short structured inquiries on transport mode and independence of mobility were attached to entries, and brief, free descriptions provided by informants were allowed, too. The method made it possible to collect more detailed data of transportation modes, as well as more qualitative, experimental information of places and affordances. Versatile data enabled triangulation and more valid findings than statistical analyses based only on behavioral patterns.

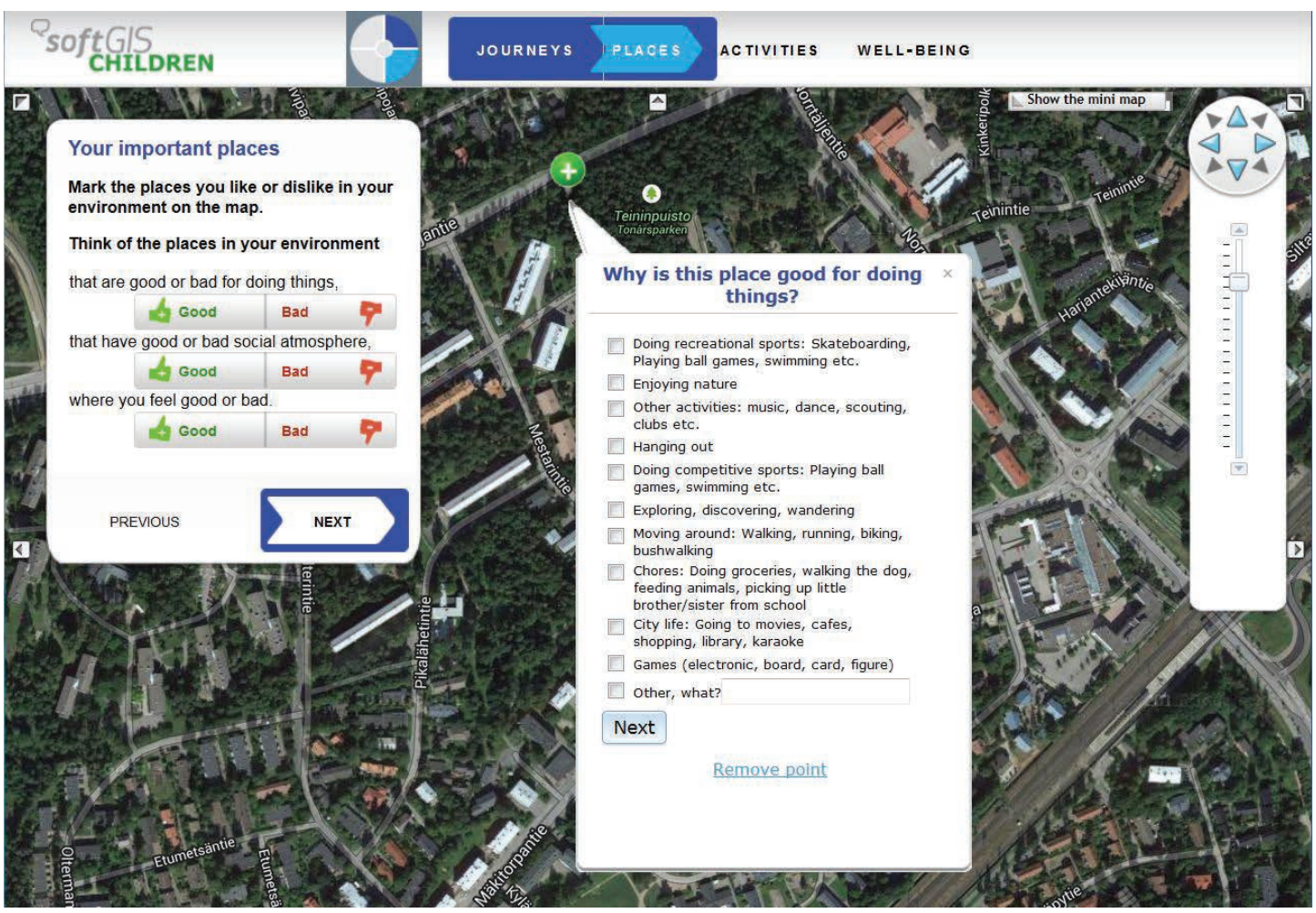

Figure 1: Pinpointing a functionally positive affordance location, i.e., a place that is good for doing things, and the follow-up questions on the affordance actualization

\subsection{Subjects}

The data was collected in 16 comprehensive schools in the Helsinki metropolitan region in Finland during the autumn and early winter of 2011, as well as in seven comprehensive schools in Tampere, Finland, during the same period in 2012. The data collection was organized in computer-equipped classrooms, led by a research assistant. An informed consent was gathered from the respondents and their parents.

A total of 895 pupils from the Helsinki region and 555 pupils from Tampere filled out the SoftGIS survey, but only a subsample of these 1450 respondents is included in this article. Participants that did not pinpoint any meaningful places or whose places were too far outside the actual study areas were excluded from the study. The number of final subjects studied for this article was 1037, of which 672 were from the Helsinki region and 365 were from Tampere. Approximately 23 percent of the participants included in the study were fifth graders and 77 percent were eighth graders (see Table 1). All the respon- 
dents from Tampere were eighth-grade students, whereas 36 percent of the respondents from Helsinki were fifth graders and 64 percent were eighth graders.

In all, 3406 places were pinpointed on the maps by children and adolescents. Places that were too far outside the study area and duplicate points, caused by a software error, were excluded. The final number of affordances included was 3307, of which 2080 were from the Helsinki region (77 excluded), and 1227 were from Tampere (22 excluded).

Table 1: Descriptive statistics of the variables used in the principle component analysis

\begin{tabular}{|c|c|}
\hline Variable Description & N (\%) / Mean (SD) \\
\hline \multicolumn{2}{|l|}{ Outcome variables } \\
\hline \multicolumn{2}{|l|}{ Transport Mode } \\
\hline Walk or cycle & $2069(67 \%)$ \\
\hline Public transportation & $721(23 \%)$ \\
\hline Car or moped & $295(10 \%)$ \\
\hline \multicolumn{2}{|l|}{ Independence } \\
\hline Alone & $856(28 \%)$ \\
\hline With friends & $2026(65 \%)$ \\
\hline With adults & $216(7 \%)$ \\
\hline \multicolumn{2}{|l|}{ Affordance category } \\
\hline Functional positive & $1140(35 \%)$ \\
\hline Functional negative & $103(3 \%)$ \\
\hline Emotional positive & $904(27 \%)$ \\
\hline Emotional negative & $228(7 \%)$ \\
\hline Social positive & $778(24 \%)$ \\
\hline Social negative & $141(4 \%)$ \\
\hline \multicolumn{2}{|l|}{ Demographic variables } \\
\hline \multicolumn{2}{|l|}{ Grade } \\
\hline 5th grader & $237(23 \%)^{*}$ \\
\hline 8th grader & $793(77 \%)^{*}$ \\
\hline \multicolumn{2}{|l|}{ City } \\
\hline Helsinki & $672(65 \%)$ \\
\hline Tampere & $365(35 \%)$ \\
\hline \multicolumn{2}{|l|}{ Physical Environmental Variables } \\
\hline \multicolumn{2}{|l|}{ Transport systems } \\
\hline Intersection density $\left(\mathrm{n} / \mathrm{km}^{2}\right)$ & $40.7(89.1)$ \\
\hline Ratio of 4-way intersections (\%) & $23.5(39.9)^{* *}$ \\
\hline Road density $\left(\mathrm{km} / \mathrm{km}^{2}\right)$ & $8.6(9.5)$ \\
\hline \multicolumn{2}{|l|}{ Land use patterns } \\
\hline Population density $\left(\mathrm{n} / \mathrm{km}^{2}\right)$ & $3991(5228)$ \\
\hline Housing density $\left(\mathrm{n} / \mathrm{km}^{2}\right)$ & $2305(3604)$ \\
\hline Area proportion of single-family housing (\%) & $9.8(22.7)$ \\
\hline Proportion of recreational areas, parks and forests (\%) & $31.6(36.3)$ \\
\hline Land use mix (Shannon's diversity index) & $0.10(0.27)$ \\
\hline Area in residential use $\left(\mathrm{m}^{2}\right)$ & $1826(2392)$ \\
\hline Area in commercial use $\left(\mathrm{m}^{2}\right)$ & $599(1821)$ \\
\hline Area in office use $\left(\mathrm{m}^{2}\right)$ & $148(722)$ \\
\hline Area in recreational use and parks $\left(\mathrm{m}^{2}\right)$ & $1031(2237)$ \\
\hline \multicolumn{2}{|l|}{ Urban design characteristics } \\
\hline Average speed limit $(\mathrm{km} / \mathrm{h})$ & $37.9(8.4)^{* * *}$ \\
\hline Maximum speed limit $(\mathrm{km} / \mathrm{h})$ & $38.6(9.2)^{* * *}$ \\
\hline Density of buildings $\left(\mathrm{n} / \mathrm{km}^{2}\right)$ & $445(479)$ \\
\hline Average grain size $\left(\mathrm{m}^{2}\right)$ & $2673(6102)$ \\
\hline Proportion of low development (\%) & $62.8(45.7)^{* * * *}$ \\
\hline Proportion of high development (\%) & $37.2(45.7)^{* * * *}$ \\
\hline
\end{tabular}




\subsection{Experiential and behavioral variables}

In the SoftGIS survey for children, the respondents used the Internet interface to mark places on a map that were functionally, emotionally, or socially meaningful for them. They also described the mode of transport they used to travel to the place, and whether they traveled independently or with adults or friends. The selectable options for the transport mode were walking or cycling, using public transport, driving a moped, and being driven in a car.

\subsection{Physical-environmental variables}

$\mathrm{BE}$ variables were analyzed using geographic information systems (GIS). Spherical buffers of 50 meters were used around each meaningful place on the map. To get a comprehensive description of the physical environment, we selected the variables evenly under the three basic components of BE defined by Frank, Engelke, and Schmid (2003): transportation systems, land-use patterns, and urban-design characteristics. As emphasized by Frank, Engelke, and Schmid (2003), these components do not operate independently from one another, but in many respects, they are related in a coherent way and logically overlap with each other. To overcome this, we formed physical environmental types that take notice of the inter-correlations between the physical-environmental variables.

\section{Variables related to transportation systems}

Street networks are an essential factor influencing the choice of trip route and mode as they define the way in which trip origins and destinations are connected (Frank, Engelke, and Schmid 2003), but previous research shows contrasting evidence in relation to the associations between pedestrian connectivity or intersection densities and children's active transportation (e.g. Wong, Faulkner, and Buliung 2011). In this study, three variables concerning street networks were calculated. Intersection density was computed by dividing the number of intersections of roads and streets inside the buffer by the area of the buffer. Also the ratio of four-way intersections to the total number of intersections within the buffer was calculated (Mitra and Buliung 2012). Road density was calculated as the total road and street length per square kilometer within the buffer (Panter et al. 2010).

\section{Variables related to land-use patterns}

The most consistently associated BE variables for youth PA are often related to land uses (Ding et al. 2011). Land-use patterns determine the degree of proximity between trip origins and destinations, and activities located closer together increase the attractiveness of bicycling and walking (Frank, Engelke, and Schmid 2003; Grow et al. 2008). In this study, land uses related to residing were analyzed with three variables: population density, housing density, and the area proportion of single-family housing. Most studies support positive correlation between residential density and youth PA (Ding et al. 2011), but also contrasting evidence has been found especially in studies conducted in Europe (De Vries et al. 2010; Broberg, Salminen, and Kyttä 2013). Population density was calculated as the number of residents per square kilometer within the buffer area (Carr, Dunsiger, and Marcus 2010). Housing density was calculated, respectively, as the number of dwellings per square kilometer (Norman et al. 2010).

Structure dominated by single-family housing is found to promote both independent mobility and use of active transport modes, particularly in Finnish context (Broberg, Salminen, and Kyttä 2013). The area proportion of single-family housing was measured as the land cover proportion of single-family housing area within the buffer.

The presence of potential youth destinations is essential in promoting PA among children and adolescents (Cradock et al. 2009). We operationalized the potential destinations with two variables: 
land-use mix, and the proportion of recreational areas, parks and forests. The diversity of land uses is one of the most consistently associated correlates for PA of children and adolescents (Ding et al. 2011). We calculated the mix of uses as the diversity of land cover proportions for residential, commercial, office, and recreational uses applying Shannon's diversity index (Shannon 1948). Also the separate measures for the acreage of each of these four land uses were calculated.

Access to recreational venues and parks is often used as a physical-environment variable in studies concerning children and adolescents, and it is also one of the most consistently associated correlates for children's PA (Pont et al. 2009; Ding et al. 2011). It also seems to have a positive effect on boys' independent mobility (Villanueva et al. 2013). In this study, the access to recreational venues and parks was operationalized as the area proportion of sports and recreational venues, parks, and forests within the buffer.

\section{Variables related to urban design characteristics}

Urban-design characteristics refer to the appearance and aesthetics of streets and sites (Frank, Engelke, and Schmid 2003). Design characteristics are not widely studied in earlier research probably because of rather limited availability of larger-scale GIS data on design features of the BE.

The speed of the motorized traffic affects the noise levels and the traffic safety of the place. According to a review by Ding et al. (2011), one of the most consistently associated correlate for PA of children is found to be traffic speed/volume. On the other hand, Wong, Faulkner, and Buliung (2011) report rather mixed associations between busy roads along or crossing the route to school and active transportation. Frank, Engelke, and Schmid (2003) consider traffic speeds an essential part of street design. The speed of traffic around the meaningful places was analyzed as the average speed limit of streets and roads within the buffer.

The appearance of sites can also be interpreted as building patterns, which we analyzed with multiple variables. The density of buildings in the buffer indicates the composition of buildings and is found to correlate with high proportions of single-family housing, which, in turn, is discovered to promote active transportation (Broberg, Salminen, and Kyttä 2013). The density of buildings was calculated as the number of buildings intersecting the buffer area per square kilometer.

Granulation forms a more sophisticated description of the building composition. We analyzed granulation with the average grain size indicating the average footprint of buildings intersecting the buffer. The height of buildings was measured as the proportions of ground area of low and high development within the buffer: low development meaning a maximum of two-story buildings and high development meaning a minimum of three-story buildings.

\subsection{GIS datasets used}

Four different geographical datasets were used to analyze the physical environment of the meaningful places marked by the respondents. The data concerning street networks and buildings, as well as topography, were mainly drawn from the Topographic Database, which is a vector based dataset produced by the National Land Survey of Finland. The dataset includes information about street and road networks, buildings, administrative borders, land uses, and topography.

The information concerning land uses was mainly calculated from the SLICES dataset (Separated Land Use and Cover Information System), which is produced by the Finnish National Land Survey. The dataset combines geographical datasets on land use from different organizations, such as the Ministry of Agriculture and Forestry, the Ministry of the Environment, the National Land Survey, and the Finnish Forest Research Institute. The dataset offers a hierarchical classification of land use, land cover, soil types, and special use and restricted areas. 
Population and housing density-related variables were drawn from the Grid Database, produced by Statistics Finland. It includes coordinate based statistical data on the population's structure, education, main type of activity, and income as well as buildings and workplaces, calculated by map grid.

The Digiroad dataset was used to analyze public transportation facilities, pedestrian and cycling networks, and traffic speeds. It is a national roads and streets database maintained by the Finnish Transport Agency, containing all streets and public, private, and forest roads in Finland, together with information on their qualities.

\subsection{Statistical analysis}

We classified the urban morphological environments around the meaningful places into six urban types by: (1) identifying 16 relevant attributes of physical urban form and computing indicators of those attributes, as described above; (2) using principal component analysis to derive generalized dimensions of these attributes; and (3) performing cluster analysis to group the variation within 50-meter buffers around the meaningful places into environmental types.

Principal component analysis with Varimax rotation and Kaiser Normalization was used to remove the redundancy and correlation in the data. To understand and distinguish the variation in physical characteristics found among the 3294 sites, we identified groups of meaningful places with similar characteristics by computing principal component scores for every meaningful place. To identify internally similar types of urban environments around the meaningful places, K-means cluster analyses were used to classify the 3294 places based on valid component loadings. The classified places were simplified into homogeneous clusters of urban morphological types on the basis of similarities and dissimilarities in the values of the principal components extracted from the previous step. (See also Yan et al. 2010; Song and Knaap 2007.)

The differences in the level of independence (alone, with friends or with an adult) and activity (walk, bike, public transport, or car/moped) of transport between different types of places were analyzed by comparing the frequencies of independence and transport modes across the urban morphology types with the chi-squared test (see Table 4). All the statistical analyses were performed with IBM SPSS Statistics 21 .

\section{Results}

Active transportation modes on the journeys to the places marked by the respondents were two times more common than passive transportation: 67 percent of the places were visited on foot or by bicycle. Only 10 percent of the trips were made with a car or a moped. Most trips were made independently, either in the company of friends (65 percent) or alone ( 28 percent) (See Table 1). The meaningful places defined by the children and youth were located rather close to the participants' homes. Over half of all of the pinpointed places were located closer than 1 kilometer from home and more than every 10th place was located within 50 meters from home. Schools were not as important of places as home neighborhoods; on average only 5.8 percent of places were located in immediate proximity to schools. In Tampere only 1 percent of places were located within 50 meters from schools, which might be due to the different age distributions between the participants in Tampere and Helsinki; in Tampere all the participants were eighth graders and in Helsinki 36 percent were fifth graders. Twenty-three percent of all places were located within 250 meters from home and 16.1 percent within 250 meters from schools (see Table 2).

To find the main dimensions of the urban morphological variables, a principal component analysis was 
Table 2: Proportions of meaningful places in home and school proximity

\begin{tabular}{|l|r|r|r|r|r|r|}
\hline & $\begin{array}{r}\text { Within } 50 \text { meters } \\
\text { from home n (\%) }\end{array}$ & $\begin{array}{r}\text { Within 250 meters } \\
\text { from home n (\%) }\end{array}$ & $\begin{array}{r}\text { Within } 1000 \text { meters } \\
\text { from home n (\%) }\end{array}$ & $\begin{array}{r}\text { Within } 50 \text { meters } \\
\text { from school n (\%) }\end{array}$ & $\begin{array}{r}\text { Within 250 meters } \\
\text { from school n (\%) }\end{array}$ & Total \\
\hline Tampere & $119(9.7 \%)$ & $275(22.4 \%)$ & $631(51.4 \%)$ & $12(1.0 \%)$ & $194(15.8 \%)$ & 1227 \\
\hline Helsinki Region & $267(12.8 \%)$ & $484(23.3 \%)$ & $1108(53.3 \%)$ & $179(8.6 \%)$ & $340(16.3 \%)$ & 2080 \\
\hline Total & $386(11.7 \%)$ & $759(23.0 \%)$ & $1739(52.6 \%)$ & $191(5.8 \%)$ & $534(16.1 \%)$ & 3307 \\
\hline
\end{tabular}

carried out. As a result, six principal components were extracted: densely populated residential areas, mainly single-family housing, traffic dominance, big commercial buildings, mixed-use areas with offices, and recreational and green areas. The loadings of the initial variables to these components are depicted in Table 3. The extracted components accounted for 74 percent of the total variation among cases on these 16 measures.

Next, we performed cluster analysis to group the meaningful places into internally homogenous urban morphology types. The best clustering solution, based on the interpretability of the results and associated cluster statistics, was found to be a six-cluster solution. The values of the cluster centroids for each of the six morphology types are depicted in Figure 2. The values associated with the centroid of a cluster are representative of a typical set of urban morphology features in that cluster, and reveal how each type differs from another in the previously derived principal component dimensions. Based on these centroid values, we labeled the six clusters or urban morphological types: (1) areas with mainly apartment buildings; (2) areas with mainly single-family housing; (3) traffic-dominated environments; (4) areas with big commercial buildings; (5) mixed-use business districts; and (6) green environments. How these different urban morphological types are present in cities of Helsinki and Tampere is presented in Figure 3.

Table 3: Loadings for PCA of variables measuring the urban morphology around the meaningful places

\begin{tabular}{|c|c|c|c|c|c|c|}
\hline & PC1 & PC2 & PC3 & PC4 & PC5 & PC6 \\
\hline & $\begin{array}{c}\text { densely } \\
\text { populated } \\
\text { residential } \\
\text { areas }\end{array}$ & $\begin{array}{l}\text { mainly } \\
\text { single } \\
\text { family } \\
\text { housing }\end{array}$ & $\begin{array}{c}\text { traffic } \\
\text { dominance }\end{array}$ & $\begin{array}{c}\text { big } \\
\text { commercial } \\
\text { buildings }\end{array}$ & $\begin{array}{l}\text { mixed-use } \\
\text { areas with } \\
\text { offices }\end{array}$ & $\begin{array}{c}\text { recreational } \\
\text { and green } \\
\text { areas }\end{array}$ \\
\hline Housing density & .928 & .019 & .140 & -.057 & .013 & .056 \\
\hline Population density & .935 & .071 & .138 & -.064 & .026 & .054 \\
\hline Proportion of min. 3-story buildings & .658 & -.140 & .133 & .419 & .277 & -.078 \\
\hline Area in residential use & .274 & .827 & .067 & -.145 & -.042 & -.038 \\
\hline Density of buildings & .038 & .887 & .168 & -.053 & .050 & .007 \\
\hline Proportion of single-family housing & -.240 & .821 & .084 & -.049 & -.043 & -.032 \\
\hline Proportion of max. 2-story buildings & -.473 & .514 & .021 & -.164 & -.177 & .184 \\
\hline Intersection density & .067 & .010 & .834 & .024 & .005 & -.037 \\
\hline Road density & .095 & .199 & .898 & -.061 & .084 & .007 \\
\hline Ratio of 4-way intersections & .136 & -.056 & .608 & .017 & .151 & -.075 \\
\hline Average speed limit & .036 & .223 & .674 & -.111 & .063 & .095 \\
\hline Area in commercial use & .014 & -.083 & -.019 & .891 & -.008 & .009 \\
\hline Average grain size & .018 & -.127 & -.092 & .876 & -.005 & .023 \\
\hline Land-use mix & .254 & .022 & .161 & .011 & .652 & .065 \\
\hline Area in office use & -.065 & -.076 & .085 & -.007 & .868 & -.028 \\
\hline Proportion of recreational areas, parks, and forests & .030 & -.013 & -.023 & .029 & .032 & .972 \\
\hline
\end{tabular}

Extraction method: Principal Component Analysis. Rotation Method: Varimax with Kaiser Normalization. 


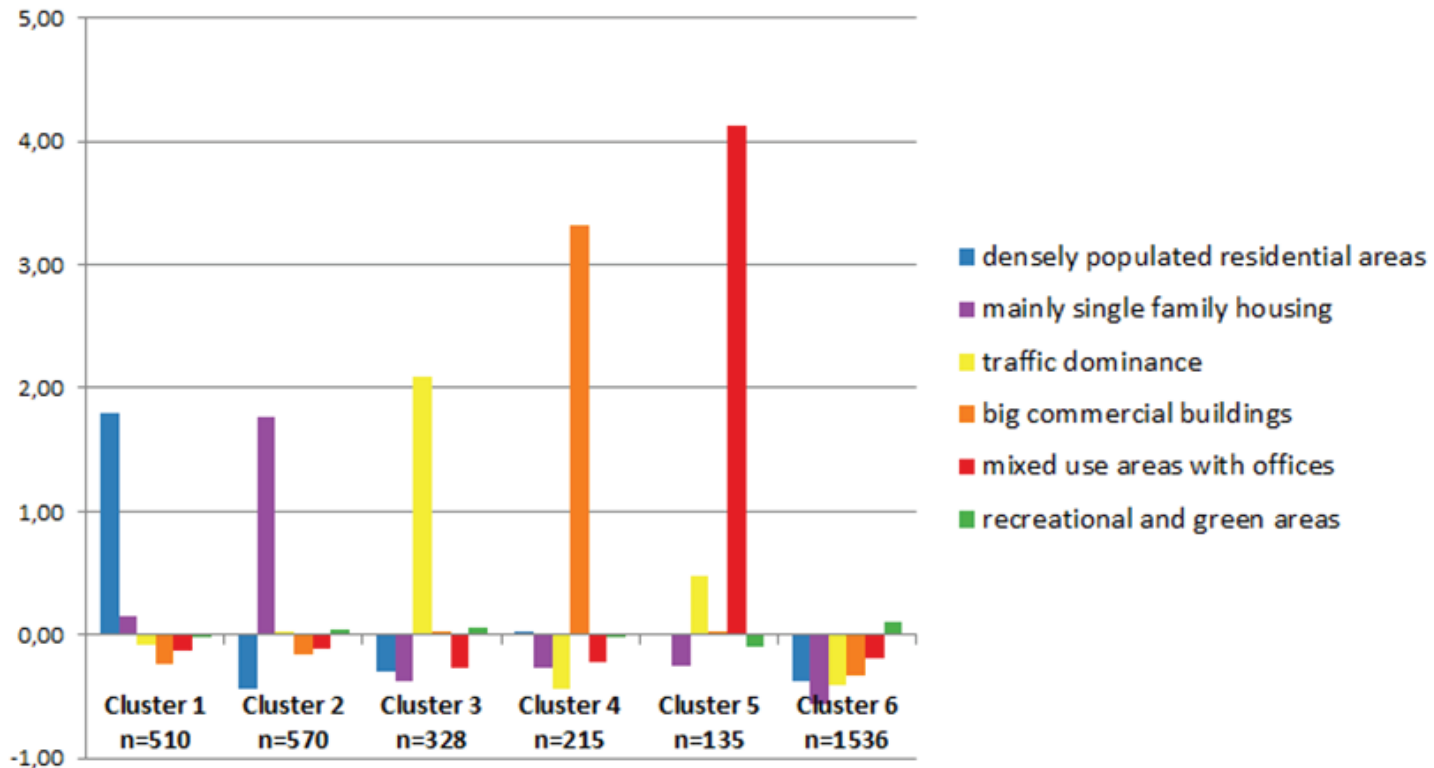

Figure 2: Cluster centroid values for each urban morphological type depicted graphically

Finally, we analyzed the transport modes and the independence of mobility to the meaningful places in each urban morphology type to see whether there were differences across types in the mobility of children and youth (see Table 4). Walking and cycling were most prominent in areas with mainly apartment buildings and areas with mainly single-family housing as well as green environments. Active transport
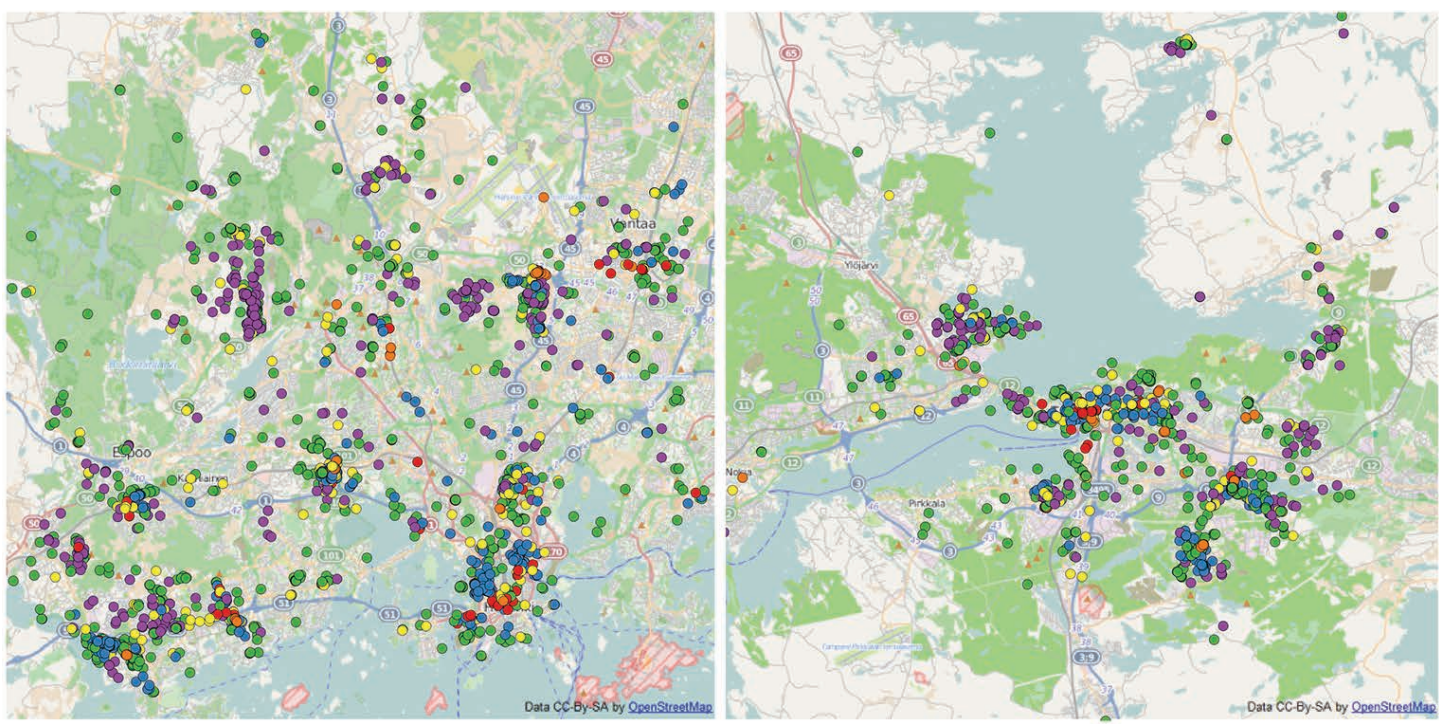

Cluster memberships of the meaningful places

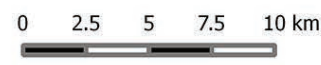

- C1: Areas with mainly apartment buildings

- C2: Areas with mainly single family housing

- C3: Traffic dominated environments

- C4: Areas with big commercial buildings

- C5: Mixed use business districts

- C6: Green environments

Figure 3: Urban morphology types of the meaningful places in Helsinki (on left) and in Tampere (on right) 
was the least common in mixed-use business districts, where public transportation was most often used to get to the places. Also areas with big commercial buildings and traffic-dominated environments had relatively high proportions of passive transportation. Car and moped were not a popular means of transport in general compared to other means of transport, but nevertheless, areas with big commercial buildings and green environments had the highest proportions of motorized transport (12 percent of all meaningful places in both environmental types). Differences in the frequencies across the urban morphology types were statistically significant for all the transport modes.

In all, the respondents came to 65 percent of their meaningful places with their friends. Areas with big commercial buildings and mixed-use business districts were most typically reached in the company of friends. Adult company was seldom reported, altogether in 7 percent of the places. Statistically significant differences were found between morphological types in respect to coming to the place alone or with friends, but no significant differences in respect to parental attendance were found.

To understand the importance of the meaningful places to the respondents, we further analyzed the occurrence of places concerning different affordance categories across the urban morphology types and the converse (see Tables 5 and 6). Meaningful places of the respondents were most often located in green environments ( 47 percent of the places) and in areas with mainly single-family housing (17 percent) and mainly apartment buildings (15 percent).

Table 4: Mode and independence of transport in the different urban morphology types

\begin{tabular}{|l|r|r|r|r|r|r|}
\hline & \multicolumn{3}{|c|}{ Transport mode } & \multicolumn{3}{c|}{ Independence of mobility } \\
\hline & $\begin{array}{c}\text { walk or } \\
\text { bike }\end{array}$ & $\begin{array}{c}\text { public } \\
\text { transportation }\end{array}$ & $\begin{array}{c}\text { car or } \\
\text { moped }\end{array}$ & alone & with friends & with adults \\
\hline C1: Areas with mainly apartment buildings & $73 \%$ & $21 \%$ & $6 \%$ & $34 \%$ & $59 \%$ & $7 \%$ \\
\hline C2: Areas with mainly single family housing & $79 \%$ & $16 \%$ & $6 \%$ & $41 \%$ & $53 \%$ & $6 \%$ \\
\hline C3: Traffic dominated environments & $54 \%$ & $36 \%$ & $10 \%$ & $28 \%$ & $63 \%$ & $8 \%$ \\
\hline C4: Areas with big commercial buildings & $48 \%$ & $40 \%$ & $12 \%$ & $7 \%$ & $85 \%$ & $8 \%$ \\
\hline C5: Mixed use business districts & $35 \%$ & $59 \%$ & $7 \%$ & $17 \%$ & $78 \%$ & $5 \%$ \\
\hline C6: Green environments & $69 \%$ & $19 \%$ & $12 \%$ & $24 \%$ & $69 \%$ & $7 \%$ \\
\hline Total \% & $67 \%$ & $23 \%$ & $10 \%$ & $28 \%$ & $65 \%$ & $7 \%$ \\
\hline Total count & 2069 & 721 & 295 & 856 & 2026 & 216 \\
\hline
\end{tabular}

Table 5: Proportions of the affordance categories across the urban morphology types

\begin{tabular}{|l|r|r|r|r|r|r|r|}
\hline & $\begin{array}{c}\text { functional } \\
\text { positive }\end{array}$ & $\begin{array}{c}\text { functional } \\
\text { negative }\end{array}$ & $\begin{array}{c}\text { emotional } \\
\text { positive }\end{array}$ & $\begin{array}{c}\text { emotional } \\
\text { negative }\end{array}$ & $\begin{array}{c}\text { social } \\
\text { positive }\end{array}$ & $\begin{array}{c}\text { social } \\
\text { negative }\end{array}$ & Total \% \\
\hline C1: Areas with mainly apartment buildings & $11.8 \%$ & $18.4 \%$ & $15.9 \%$ & $14.0 \%$ & $19.0 \%$ & $23.4 \%$ & $15.5 \%$ \\
\hline C2: Areas with mainly single family housing & $9.8 \%$ & $8.7 \%$ & $22.9 \%$ & $6.1 \%$ & $26.2 \%$ & $17.0 \%$ & $17.3 \%$ \\
\hline C3: Traffic dominated environments & $10.4 \%$ & $13.6 \%$ & $8.6 \%$ & $11.8 \%$ & $9.6 \%$ & $10.6 \%$ & $10.0 \%$ \\
\hline C4: Areas with big commercial buildings & $9.6 \%$ & $3.9 \%$ & $7.0 \%$ & $3.5 \%$ & $3.7 \%$ & $.7 \%$ & $6.5 \%$ \\
\hline C5: Mixed use business districts & $5.6 \%$ & $4.9 \%$ & $3.0 \%$ & $4.4 \%$ & $2.7 \%$ & $5.7 \%$ & $4.1 \%$ \\
\hline C6: Green environments & $52.7 \%$ & $50.5 \%$ & $42.6 \%$ & $60.1 \%$ & $38.7 \%$ & $42.6 \%$ & $46.6 \%$ \\
\hline Total counts & 1140 & 103 & 904 & 228 & 778 & 141 & 3294 \\
\hline
\end{tabular}

Table 6: Proportions of the urban morphology types across the affordance categories

\begin{tabular}{|l|r|r|r|r|r|r|r|}
\hline & $\begin{array}{c}\text { functional } \\
\text { positive }\end{array}$ & $\begin{array}{r}\text { functional } \\
\text { negative }\end{array}$ & $\begin{array}{c}\text { emotional } \\
\text { positive }\end{array}$ & $\begin{array}{c}\text { emotional } \\
\text { negative }\end{array}$ & $\begin{array}{c}\text { social } \\
\text { positive }\end{array}$ & $\begin{array}{c}\text { social } \\
\text { negative }\end{array}$ & $\begin{array}{c}\text { Total } \\
\text { counts }\end{array}$ \\
\hline C1: Areas with mainly apartment buildings & $26.4 \%$ & $3.7 \%$ & $28.2 \%$ & $6.3 \%$ & $29.0 \%$ & $6.5 \%$ & 511 \\
\hline C2: Areas with mainly single family housing & $19.6 \%$ & $1.6 \%$ & $36.3 \%$ & $2.5 \%$ & $35.8 \%$ & $4.2 \%$ & 570 \\
\hline C3: Traffic dominated environments & $36.3 \%$ & $4.3 \%$ & $23.8 \%$ & $8.2 \%$ & $22.9 \%$ & $4.6 \%$ & 328 \\
\hline C4: Areas with big commercial buildings & $50.9 \%$ & $1.9 \%$ & $29.4 \%$ & $3.7 \%$ & $13.6 \%$ & $0.5 \%$ & 214 \\
\hline C5: Mixed use business districts & $47.4 \%$ & $3.7 \%$ & $20.0 \%$ & $7.4 \%$ & $15.6 \%$ & $5.9 \%$ & 135 \\
\hline C6: Green environments & $39.1 \%$ & $3.4 \%$ & $25.1 \%$ & $8.9 \%$ & $19.6 \%$ & $3.9 \%$ & 1536 \\
\hline Total \% & $34.6 \%$ & $3.1 \%$ & $27.4 \%$ & $6.9 \%$ & $23.6 \%$ & $4.3 \%$ & 3294 \\
\hline
\end{tabular}


Most places were considered functionally (38 percent) meaningful. Thirty-four percent were considered emotionally meaningful and 28 percent socially meaningful. These categories of meaningful places were not spread evenly across the environmental types. Mixed-use business districts and areas with big commercial buildings more often had functional meanings than did other places, and the functional meanings were also assessed relatively more positive than other environmental types. However, mixeduse business districts had relatively more negative assessments in other categories, whereas areas with big commercial buildings were emotionally more positive and socially rather neutral. In areas with mainly apartment buildings, social meanings were emphasized and in a relatively negative way. In areas with mainly single-family housing, functional meanings were far less important than emotional and social meanings, and the emotional and social aspects were also assessed more positively than in other environments. Green environments were especially important settings for functional positive affordances as well as for emotionally negative affordances, though it must be noted that selecting negative affordance places was not very general among respondents. Traffic-dominated environments were relatively more negatively than positively assessed in every category compared to other environmental types. The differences in frequencies of affordance categories across different morphological types were statistically significant $\left(\chi^{2}=221.75, \mathrm{df}=25, \mathrm{p}=.000\right)$.

All in all, the places that were most negatively assessed and were reached most often with passive transport modes were traffic-dominated environments and mixed-use business districts. The best places from the aspect of active transportation and independent mobility as well as positive meanings were areas with mainly single-family housing.

\section{Discussion}

This study systematically identified six urban morphological types in two city regions in Finland. The resulting types reflected quite closely the commonly known types of urban environments. Also worth noting is that each urban morphology type was depicted by one principal component.

These types form a very rough framework to be utilized in urban design, and more research is needed to create more usable guidelines. Hence, this study provides knowledge about how walkable and bikeable the typical neighborhoods of Finnish cities are for children and youth. Still, six purely built environmental types offer a relatively diverse description of the physical environment compared to many other related studies, as the BE is often classified into three or four types (Boone-Heinonen et al. 2010; Yan et al. 2010; Norman et al. 2010).

Often neighborhoods and their characteristics are classified based on where they fit along the range set by traditional central-city and conventional suburban neighborhoods (Mitra and Buliung 2014) or rural-to-urban continuum (Song and Knaap 2007). This can clearly be seen in many recent related studies (Yan et al. 2010, Norman et al. 2010, Nelson et al. 2006). According to Mitra and Buliung (2014), predicting walking mode choice of children is less accurate at the intersections of these environmental types. In this study, we did not classify the environmental types on the basis of how they are located in the urban, suburban, or rural zones of the traditional city structure. However, in Figure 3 it is shown that some patterns can be recognized. Places characterized by mainly single-family housing are typically scattered around the outskirts of the city, whereas mixed-use business districts, areas with big commercial buildings, and areas with mainly apartment buildings are, for the most part, concentrated in central areas and larger suburbs. However, green and traffic-dominated environments were, in general, spread across the city and do not fit easily along the central-suburban continuum. A relatively similar classification can be found in a study conducted in the United States by Song and Knaap (2007), where six neighborhood types were determined based on $21 \mathrm{BE}$ variables: four neighborhood types could be lined up on a range from "sporadic rural developments" to "downtown, inner and middle ring-suburban re- 
developments/infill," whereas "composite greenfields" and "partially clustered greenfields" could be classified as hybrid types that do not fit effortlessly into the rural-urban continuum. It must also be noted that the 21 individual $\mathrm{BE}$ variables had many similarities compared to our study. This note encourages study of the BE through environmental types, since it might produce more universal typologies in different countries and continents and thus open new possibilities in studying the BE.

The frequency of walking and cycling was fairly high at 67 percent of all pinpointed places. The findings from previous studies vary from similar results (Rothman et al. 2014; Jones, Davis, and Eyers 2000) to lower rates of walking (Buliung, Mitra, and Faulkner 2009; Martin, Lee, and Lowry 2007). However, the transport mode should not be the only consideration when thinking about the possibilities of different urban settings to promote activity—children's possibilities for moving independently, be it on foot or by public transport— should be considered (Broberg, Salminen, and Kyttä 2013). Children enjoying higher levels of independence, show higher levels of objectively measured physical activity, compared to those with more restricted mobility patterns (see, e.g., Stone et al. 2014; Mitra et al. 2014; Schoeppe et al. 2014; Page et al. 2009). As stated by Kyttä et al. (2014), Finnish children and young people are also, in terms of international comparisons, very independent in their mobility. This study also supports this finding, as parents were accompanying only 7 percent of the trips. It is also worth noting that most places were reached in the company of friends, and as Mikkelsen and Christensen (2009) observed in Danish children, the independence of mobility is not necessarily moving alone, but moving without adults, among peers.

In this study, especially residential environments allowed for walking and cycling, whereas mixeduse and commercial environments were reached by public transportation. Most car use was reported on trips directed to commercial or green spaces. We made a similar finding earlier concerning mobility to shopping mall types of environments (Broberg, Salminen, and Kyttä 2013). This supports the hypothesis that composing multivariate profiles of the physical environment might produce more consistent results in respect to active transportation among children and adolescents, at least in Finnish context. As noted above, applying this method to different contexts and countries could help us find more uniform correlations between $\mathrm{BE}$ and $\mathrm{PA}$.

Comparing our results with earlier research can be difficult due to very diverse sets of $\mathrm{BE}$ and other variables and consequently diverse classifications of environmental types across studies. According to a review conducted by Pont et al. (2009), the most potential positive built environmental correlates of children's active transportation are found to be parks and recreational facilities, mixed-land use, centralcity/urban environment, and population density. This corresponds to our findings, except for centralcity environments often dominated by mixed-use business districts, which were more often visited by public transportation in our study. As there is more infrastructure for public transportation per capita in European cities compared to North American cities (van de Coevering and Schwanen 2006), we can speculate that perhaps public transportation in Finland is somewhat better in international comparison, and probably Finnish children are allowed to use public transport more independently (Kyttä et al. 2014), which makes it a more usual transport mode for children in Finland. However, the different research setting more likely explains this result. In most studies, the BE around home location is under the scope (e.g. Mitra, Buliung, and Roorda 2010; Larsen et al. 2009; Panter et al. 2010), whereas in this study the focus is at the destination environments. Together with the fact that distance from home is the most consistent negative correlate of active transportation of children (e.g., Pont et al. 2009; Mitra and Buliung 2014; Larsen et al. 2009), it is evident that central environments with mixed land use are less likely to be traveled to on foot or by bicycle than are residential environments where the children mainly live.

Next we need more detailed information about the nuances within the basic environmental types 
to define the moderators to the effects of the BE on youth active transportation. That is, how do we make these environmental types as walkable and bikeable for youth as they can be? According to research by Mitra and Buliung (2012), using a relatively small buffer size may produce unreliable statistical results, and in contrast, generalizing the value of a $\mathrm{BE}$ variable with larger buffer size will typically reduce the sample variance, while increasing the correlation between separate BE variables. They also discovered that the statistical significance and the size of the coefficients vary noticeably across different scales of analysis (Mitra and Buliung 2012). In this study, a 50-meter buffer was used around the meaningful places, which is a relatively small buffer size (e.g. Mitra and Buliung 2014; Song and Knaap 2007; Boone-Heinonen et al. 2010). Considering this, perhaps using different scales, i.e., multiple buffer sizes, concurrently in future studies could help create more subtle environmental types to assist urban designers to compose better environments to promote PA. In further analysis it would also be worthwhile to study the affordances the children and youth have indicated in their meaningful places more closely, to analyze the motivational factors of coming to these places, and the affordances that different urban morphology types can offer to the youngsters.

\section{$5 \quad$ Limitations}

Some limitations concerning the statistical methods used occur in this research. First, considering the principal component analysis performed, the Varimax rotation used is only applicable to scenarios where the factors are not correlated with one another. The PC6 (recreational and green areas) was in significant negative correlation with all the other factors apart from PC2 (mainly single-family housing), which somewhat undermines the analysis. However, only one of the original variables loaded to the PC6, namely the proportion of recreational areas, parks, and forests.

Second, the distance between home and a meaningful place was not taken into account in this study. This might cause some bias in the results by, for example, emphasizing the level of active transportation in residential areas.

In addition, data on what time of day the affordances took place was not collected in this study. Consequently, the study does not take into account the changes in activity participation at different times of day, although it might have an impact on activity patterns.

\section{Acknowledgements}

We would like to thank the headmasters, teachers, and pupils in the participating schools for their valuable input. The research was carried out in collaboration with three research institutes, Tampere University of Technology, The Aalto University, and the UKK institute. The project was funded by the Ministry of Education and Culture, and it joined the SKIDIT-KIDS program of the Academy of Finland. 


\section{References}

Boone-Heinonen J., K. Evenson, Y. Song, and P. Gordon-Larsen. 2010. Built and socioeconomic environments: Patterning and associations with physical activity in US adolescents. International Journal of Behavioral Nutrition and Physical Activity 7: 45.

Broberg, A., M. Kyttä, and N. Fagerholm. 2013. Child-friendly urban structures: Bullerby revisited. Journal of Environmental Psychology 35(0): 110-120.

Broberg A., S. Salminen, and M. Kyttä. 2013. Physical environmental characteristics promoting independent and active transport to children's meaningful places. Applied Geography 38: 43-52.

Buliung R. N., R. Mitra, and G. Faulkner. 2009. Active school transportation in the Greater Toronto area, Canada, an exploration of trends in space and time (1986-2006). Preventive Medicine 48: 507-512.

Carr L., S. Dunsiger, and B. Marcus. 2010. Walk score as a global estimate of neighborhood walkability. American Journal of Preventive Medicine 39(5): 460-463.

Cervero R., and M. Duncan. 2003. Walking, bicycling, and urban landscapes: Evidence from the San Francisco bay area. American Journal of Public Health 93(9): 1478-1483.

Cradock A., S. Melly, J. Allen, J. Morris, and S. Gortmaker. 2009. Youth destinations associated with objective measures of physical activity in adolescents. Journal of Adolescent Health 45: S91-S98.

De Vries S., M. Hopman-Rock, I. Bakker, R. Hirasing, and W. Van Mechelen. 2010. Built environmental correlates of walking and cycling in Dutch urban children: Results from the Space study. International Journal of Environmental Research and Public Health 7: 2309-2324.

Ding D., J. Sallis, J. Kerr, S. Lee, and D. Rosenberg. 2011. Neighborhood environment and physical activity among youth: A review. American Journal of Preventive Medicine 41(4): 442-455.

Frank L., P. Engelke, and T. Schmid. 2003. Health and Community Design: The Impact of the Built Environment on Physical Activity. Washington DC: Island Press.

Frank, L., M. Andresen, and T. Schmid. 2004. Obesity relationships with community design, physical activity, and time spent in cars. American Journal of Preventive Medicine 27(2): 87-96.

Frank L., J. Kerr, J. Chapman, and J. Sallis. 2007. Urban form relationships with walk trip frequency and distance among youth. The Science of Health Promotion 21(4): 305-311.

Frank L., J. Kerr, J. Sallis, R. Miles, and J. Chapman. 2008. A hierarchy of socio-demographic and environmental correlates of walking and obesity. Preventive Medicine 47: 172-178.

Gibson J. 1986. The Ecological Approach to Visual Perception. Hillsdale, New Jersey: Lawrence Erlbaum Associates.

Grow H., B. Saelens, J. Kerr, N. Durant, G. Norman, and J. Sallis. 2008. Where are youth active? Roles of proximity, active transport, and built environment. Medicine and Science in Sports and Exercise 40(12): 2071.

Heft, H. 1988. Affordances of children's environments: A functional approach to environmental description. Children's Environments Quarterly 5(3): 29-37.

Heft, H. 2001. Ecological Psychology in Context: James Gibson, Roger Barker, and the Legacy of William James's Radical Empirism. Mahwah, NJ: Lawrence Erlbaum Associates.

Jones L., A. Davis, and T. Eyers. 2000. Young people, transport and risk: Comparing access and independent mobility in urban, suburban and rural environments. Health Education Journal 59: 315-328.

Kahila, M., and M. Kyttä. 2009. SoftGIS as a bridge-builder in collaborative urban planning. In Planning Support Systems Best Practice andNew Methods, edited by S. Geertman, and J. Stillwell, 389-411. Dordrecht, Netherlands: Springer. 
Kerr J., L. Frank, J. Sallis, and J. Chapman. 2007. Urban form correlates of pedestrian travel in youth: Differences by gender, race-ethnicity and household attributes. Transportation Research Part D 12: 177-182.

Kyttä, M. 2002. Affordances of children's environments in the context of cities, small towns, suburbs and rural villages in Finland and Belarus. Journal of Environmental Psychology 22(1-2): 109-123.

Kyttä, M., A. Broberg, and M. Kahila. 2012. Urban environment and children's active lifestyle: SoftGIS revealing children's behavioral patterns and meaningful places. American Journal of Health Promotion 26(5): e137-e148.

Kyttä, M., J. Hirvonen, I. Pirjola, T. Laatikainen, and J. Rudner. 2014. The last free-range children? Children's independent mobility in Finland in 1990s and 2010s. In review, Journal of Transport Geography.

Larsen K., J. Gilliland, P. Hess, P. Tucker, J. Irwin, and M. He. 2009. The influence of the physical environment and socio-demographic characteristics on children's mode of travel to and from school. American Journal of Public Health 99(3): 520-526.

Malina R. 2001. Physical activity and fitness: Pathways from childhood to adulthood. American Journal of Human Biology 13: 162-172.

Martin S. L., S. M. Lee, and R. Lowry. 2007. National prevalence and correlates of walking and bicycling to school. American Journal of Preventive Medicine 33: 98-105.

Mikkelsen, M. R., and P. Christensen. 2009. Is children's independent mobility really independent? A study of children's mobility combining ethnography and GPS/mobile phone technologies. Mobilities 4(1): 37-58.

Mitra, R., R. Buliung, and M. Roorda. 2010. Built environment and school travel mode choice in Toronto, Canada. Transportation Research Record: Journal of the Transportation Research Board 2156(1): $150-159$.

Mitra R., and R. Buliung. 2012. Built-environment correlates of active school transportation: Neighborhood and the modifiable areal unit problem. Journal of Transport Geography 20: 51-61.

Mitra R., and R. Buliung. 2014. The influence of neighborhood environment and household travel interactions on school travel behavior: An exploration using geographically-weighted models. Journal of Transport Geography 36: 69-78.

Mitra, R., G. E. Faulkner, R. N. Buliung, and M. R. Stone. 2014. Do parental perceptions of the neighborhood environment influence children's independent mobility? Evidence from Toronto, Canada. Urban Studies 51(16): 3401-3419.

Moudon, A. V. 1994. Getting to know the built landscape: Typomorphology. In Ordering Space: Types in Architecture and Design, edited by K. A. Franck, and L. H. Schneekloth. New York: Van Nostrand Reinhold.

Moudon A. V. 1997. Urban morphology as an emerging interdisciplinary field. Urban Morphology 1: $3-10$.

Nelson M., P. Gordon-Larsen, Y. Song, and B. Popkin. 2006. Built and social environments: Associations with adolescent overweight and activity. American Journal of Preventive Medicine 31(2): 109117.

Norman G., M. Adams, J. Kerr, S. Ryan, L. Frank, and S. Roesch. 2010. A latent profile analysis of neighborhood recreation environments in relation to adolescent physical activity, sedentary time, and obesity. Journal of Public Health Management and Practice 16(5): 411-419.

Page, A. S., A. R. Cooper, P. Griew, L. Davis, and M. Hillsdon. 2009. Independent mobility in relation to weekday and weekend physical activity in children aged 10-11 years: The PEACH Project. International Journal of Behavioral Nutrition and Physical Activity 6: 2-11. 
Panter, J. R., A. P. Jones, E. M. F. Van Sluijs, and S. J. Griffin. 2010. Neighborhood, route, and school environments and children's active commuting. American Journal of Preventive Medicine 38(3): 268278.

Pont K., J. Ziviani, D. Wadley, S. Bennett, and R. Abbott. 2009. Environmental correlates of children's active transportation: A systematic literature review. Health and Place 15: 849-862.

Rothman L., T. To, R. Buliung, C. Macarthur, and A. Howard. 2014. Influence of social and built environment features on children walking to school: An observational study. Preventive Medicine 60: $10-15$.

Schoeppe, S., M. J. Duncan, H. M. Badland, M. Oliver, and M. Browne. 2014. Associations between children's independent mobility and physical activity. BMC Public Health 14(1): 91.

Shannon C. 1948. A mathematical theory of communication. The Bell System Technical Journal 27: 379-423, 623-656.

Song, Y., and G. Knaap. 2007. Quantitative classification of neighborhoods: The neighborhoods of new single-family homes in the Portland metropolitan area. Journal of Urban Design 12(1): 1-24.

Stone, M.R., G. E. Faulkner, R. Mitra, and R. N. Buliung. 2014. The freedom to explore: Examining the influence of independent mobility on weekday, weekend and after-school physical activity behavior in children living in urban and inner-suburban neighborhoods of varying socioeconomic status. International Journal of Behavioral Nutrition and Physical Activity 11(1): 5.

van de Coevering P., and Schwanen T. 2006. Re-evaluating the impact of urban form on travel patterns in Europe and North-America. Transport Policy 13: 229-239.

Villanueva K., B. Giles-Corti, M. Bulsara, G. McGormack, A. Timperio, N. Middleton, B. Beesley, and G. Trapp. 2012. How far do children travel from their homes? Exploring children's activity spaces in their neighborhood. Health and Place 18: 263-273.

Villanueva K., B. Giles-Corti, M. Bulsara, A. Timperio, G. McCormack, B. Beesley, G. Trapp, and N. Middleton. 2013. Where do children travel to and what local opportunities are available? The relationship between neighborhood destinations and children's independent mobility. Environment and Behavior 45(6): $679-705$.

Wong, B., G. Faulkner, and R. Buliung. 2011. GIS measured environmental correlates of active school transport: A systematic review of 14 studies. International Journal of Behavioral Nutrition and Physical Activity 8(39): 1-22.

Yan, A. F., C. C. Voorhees, K. Clifton, and C. Burnier. 2010. Do you see what I see? Correlates of multidimensional measures of neighborhood types and perceived physical activity-related neighborhood barriers and facilitators for urban youth. Preventive Medicine 50(Suppl.): S18-S23. 